\title{
ENTRE A PRÁTICA DE EXAMES E A PERSPECTIVA FORMATIVA: AVALIAÇÃO DA APRENDIZAGEM A PARTIR DO OLHAR DOS DISCENTES DO ENSINO MÉDIO INTEGRADO
}

\author{
Raimar Antonio Rodrigues Leitão*; Vanderlei Antonio Stefanuto \\ E-mail: raimar.antonio@ifam.edu.br; vanderstefanuto13@gmail.com \\ *Instituto Federal de Educação, Ciência e Tecnologia do Amazonas \\ DOI: 10.15628/rbept.2020.9912
}

Artigo submetido em: Abr/2020 e aceito em: Mai/2020

\begin{abstract}
RESUMO
Este estudo objetiva compreender a percepção dos discentes do Ensino Médio Integrado sobre a avaliação da aprendizagem, frente ao caráter histórico da prática de exames e à perspectiva formativa da avaliação. Como metodologia, utilizou-se a pesquisa bibliográfica, seguida da pesquisa de campo realizada por meio de uma entrevista semiestruturada. Por se tratar de discentes do Ensino Médio Integrado, são destacadas considerações sobre a Formação Humana Integral, como uma das principais bases da Educação Profissional e Tecnológica EPT, a qual contempla a oferta do Ensino Médio Integrado. Os dados levantados sugerem que a avaliação permanece entrelaçada à prática de exames, o que demanda a indicação da avaliação formativa para melhor atender aos anseios de aprendizagem e de Formação Humana Integral dos discentes.
\end{abstract}

Palavras-chave: Exames. Avaliação Formativa. Formação Humana Integral.

\section{BETWEEN THE EXAMS PRACTICE AND THE FORMATIVE PERSPECTIVE: LEARNING EVALUATION IN THE VIEW OF INTEGRATED HIGH SCHOOL STUDENTS}

\begin{abstract}
This study aims to understand the perception of Integrated High School students about the learning evaluation, in view of the historical character of exams practice and the formative perspective of the evaluation. As methodology, was used the bibliographic research, followed by field research carried out through a semi-structured interview. Since it is about students of the integrated high school, considerations about the Integral Human Formation are highlighted, as one of the main bases of Professional and Technological Education - PTE, which contemplates the offer of the Integrated High School. The data collected suggest that the evaluation remains interconnected with the exams practice, which requires the indication of formative evaluation to better meet the students' learning and Integral Human Formation aspirations.
\end{abstract}

Keywords: Exams. Formative Evaluation. Integral Human Formation. 


\section{INTRODUÇÃO}

As informações apresentadas neste artigo constituem um recorte e um desdobramento da pesquisa de Mestrado $^{1}$ em desenvolvimento, intitulada "Avaliação da Aprendizagem: contribuições para a Formação Humana Integral de discentes do Ensino Médio Integrado."

À medida que nos propomos a discutir sobre avaliação, naturalmente somos conduzidos a refletir sobre diversos aspectos que precedem, se entrelaçam e transcendem os processos avaliativos ${ }^{2}$. Antes de pensar em avaliar, é preciso proporcionar oportunidades coerentes de aprendizagens para os diferentes perfis discentes (aquilo que precede). $E$, paralelamente ao processo avaliativo, devemos levar em consideração as distintas formas de expressão da aprendizagem por parte dos discentes, frente aos objetivos estabelecidos para 0 alcance dos resultados pretendidos (aquilo que entrelaça). Além disso, necessitamos considerar os eventuais resultados expressos pelo rendimento acadêmico, com consequências para a progressão dos discentes dentro do sistema escolar e, a posteriori, na sua inserção social e profissional no mundo do trabalho (aquilo que transcende).

Nessa conjuntura, abordaremos a temática avaliação da aprendizagem a partir do olhar discente, relacionando-a ao caráter histórico da prática de exames e indicando a avaliação formativa como uma alternativa mais coerente para o ato de avaliar e contribuir com o desenvolvimento da Formação Humana Integral dos alunos.

Para tanto, fizemos uma imersão ao levantamento de relevantes informações distribuídas nas seguintes seções: "Referencial Teórico", "Metodologia" e "Avaliação da Aprendizagem a partir do olhar dos discentes do Ensino Médio Integrado", tendo como referências principais, teóricos como Ciavatta (2005), Depresbiteris (1989; 1998), Hadji (2001), Luckesi (2011), Perrenoud (1999), Ramos (2008; 2017) e Lopes e Silva (2012), entre outros.

Dentro da metodologia adotada, utilizamos a pesquisa bibliográfica entremeada à pesquisa de campo por meio da aplicação de uma entrevista semiestruturada. As informações coletadas, tanto de cunho bibliográfico como empírico, se complementam e, dialogando entre si, possibilitam o caminhar na direção estabelecida pelo objetivo deste estudo, qual seja, compreender a percepção dos discentes do Ensino Médio Integrado sobre avaliação da

\footnotetext{
${ }^{1}$ A pesquisa de mestrado encontra-se abrangida pela Linha de Pesquisa "Práticas Educativas em Educação Profissional e Tecnológica (EPT)”, uma das linhas de pesquisa do Programa de Mestrado Profissional em Educação Profissional e Tecnológica - ProfEPT. Disponível em: https://profept.ifes.edu.br/. Acesso em: 11 mar. 2020.

2 Dependendo da abordagem pedagógica e da finalidade a que se propõe o processo ensinoaprendizagem de modo geral, ao qual vinculam-se as ações em torno da avaliação da aprendizagem, naturalmente derivarão visões distintas sobre o processo avaliativo. Dentro da abordagem sócio-cultural, por exemplo, alinhada ao pensamento de Paulo Freire, o processo avaliativo "consiste na auto-avaliação e/ou avaliação mútua e permanente sobre a prática educativa, por parte de professores e alunos, ou seja, considerando tal prática em todos os seus aspectos, sem se restringir à avaliação de conteúdos. Desse modo, qualquer processo formal de exames deixa de ter sentido." (SILVA, C.; SILVA, A.; OLIVEIRA, 2007, p. 432).
} 
aprendizagem, frente ao caráter histórico da prática de exames e a perspectiva formativa da avaliação.

\section{REFERENCIAL TEÓRICO}

\subsection{ENSINO MÉDIO INTEGRADO E FORMAÇÃO HUMANA INTEGRAL}

Considerando o ambiente de imersão dos participantes desta pesquisa, trazemos inicialmente à tona alguns esclarecimentos sobre o Ensino Médio Integrado e a Formação Humana Integral. O primeiro elemento corresponde à forma de Ensino Médio (integrada) ofertada aos participantes, enquanto o segundo refere-se a uma das bases conceituais da EPT (Formação Humana Integral) que deve ser desenvolvida dentro do Ensino Médio Integrado.

Sobre a integração que deve ocorrer no Ensino Médio, partindo-se do ponto de vista organizacional, o Documento Base para a Educação Profissional Técnica de Nível Médio (2007, p. 47) orienta que se:

[...] deve integrar em um mesmo currículo a formação plena do educando, possibilitando construções intelectuais elevadas; a apropriação de conceitos necessários para a intervenção consciente na realidade e a compreensão do processo histórico de construção do conhecimento.

Tais orientações convergem na direção de uma formação integral do discente, que the possibilite compreender e galgar os patamares elevados do conhecimento, habilitando-o a atuar conscientemente na realidade. $O$ que, consequentemente, Ihe possibilitará contribuir de modo mais eficiente com o progresso da sociedade, para além do exercício de profissões técnicas.

Nessa esteira, entre os "Princípios Norteadores para a Educação Profissional Técnica de Nível Médio" apresentados no Art. $6^{\circ}$ da Res. $\mathrm{n}^{\circ}$ 06/2012, do Conselho Nacional de Educação - CNE, destacamos o que regem, respectivamente, os incisos de I a IV, abaixo transcritos:

I - relação e articulação entre a formação desenvolvida no Ensino Médio e a preparação para o exercício das profissões técnicas, visando à formação integral do estudante; II - respeito aos valores estéticos, políticos e éticos da educação nacional, na perspectiva do desenvolvimento para a vida social e profissional; III - trabalho assumido como princípio educativo, tendo sua integração com a ciência, a tecnologia e a cultura como base da proposta político-pedagógica e do 
desenvolvimento curricular; IV - articulação da Educação Básica com a Educação Profissional e Tecnológica, na perspectiva da integração entre saberes específicos para a produção do conhecimento e a intervenção social, assumindo a pesquisa como princípio pedagógico. (BRASIL, 2012, p. 2).

As informações apresentadas por meio desses quatro princípios sinalizam para a amplitude da formação que deve ser proporcionada aos estudantes durante o Ensino Médio Integrado. São diversos os aspectos e os valores, que superam o mero oferecimento da formação do ensino médio e/ou técnica aos estudantes. Dada a importância de uma formação propiciada nos moldes acima sugeridos, Ciavatta (2005) acrescenta que, no que tange a formação integrada ou do ensino médio integrado ao ensino técnico, almeja-se que a educação geral seja uma dimensão inerente à educação profissional em todas as áreas onde acontece a capacitação para o trabalho desde os processos produtivos e educativos, tais como a formação inicial, o ensino técnico, o tecnológico e o superior.

Para além dos processos educativos, Ramos (2017) endossa a importância e abrangência do Ensino Médio Integrado, ao considerar que ele compreenderia o ser humano como fruto das relações histórico-sociais e, nesses termos, a própria realidade. Trata-se, portanto, da formação humana como ação de reprodução dessa realidade em cada ser, de maneira que ele possa apreendê-la, criticá-la e modificá-la. Assim, o projeto político-pedagógico objetiva integrar as dimensões essenciais da práxis social, trabalho, ciência e cultura, na formação dos estudantes.

Tais dimensões apresentadas por Ramos nos remetem ao principal alvo do Ensino Médio Integrado, a saber, a Formação Humana Integral/Omnilateral. (BEZERRA, 2013).

Ainda segundo Ramos (2008), a formação humana em seu sentido completo somente é capaz de ser atingida quando o indivíduo amplia suas capacidades, no sentido de habilitar-se para decidir e agir amparado na união entre trabalho intelectual e manual, ou seja, integrando teoria e prática a favor da formação plena do discente. De modo bem similar ao que já abordamos inicialmente ao caracterizar o Ensino Médio Integrado, a Formação Humana Integral igualmente requer a superação da dualidade e a consequente consolidação da unidade entre a ação intelectual e a manual. Contudo, a afirmação de Ramos destaca outros dois aspectos relevantes: capacidade de decisão e ação.

A fomentação de tais aspectos, entre outros, é de suma importância no processo formativo escolar, sobretudo para o público do Ensino Médio Integrado, para que os seus egressos possam tornar-se indivíduos imbuídos de habilidade de decisão e atuação propositiva, emancipatória e favorável ao bem-estar e desenvolvimento da sociedade. Nesta mesma linha de entendimento, Estrela (2017) reforça que somente uma formação humana que recomenda a integração de todas as dimensões da vida (entre as quais estão trabalho, lazer, ciência e cultura) está apta a oferecer para os indivíduos um 
entendimento relativo ao processo histórico das produções científicas, tecnológicas e culturais. A autora discorre ainda que uma educação de caráter emancipatório permitirá o domínio do conhecimento, viabilizando a participação de todos na vida social.

No tocante às discussões em torno desta temática tão significativa, especialmente na conjuntura do Ensino Médio Integrado, Bemvindo, Almeida e Turrini (2013) destacam, dentro das considerações de Marx, o trabalho como elemento central e principal atividade humana.

Para Marx, a formação humana deve ter o trabalho como elemento central. $O$ trabalho é necessariamente o princípio educativo, pois o homem historicamente tem produzido a sua existência através do mesmo, sendo esta, então, a principal atividade humana. Porém, não se trata de qualquer trabalho, mas o mesmo entendido como meio pelo qual o homem transforma a natureza e a si mesmo diferenciando-se assim, dos outros animais. Neste processo, o homem se humaniza por meio do trabalho, agindo sobre a realidade objetiva, humanizando o mundo [...]. (BEMVINDO; ALMEIDA; TURRINI, 2013, p. 8).

Além do papel proeminente do trabalho no cenário da formação humana - fator transformador do próprio homem, da natureza e do mundo a sua volta -, a Formação Humana Integral também diz respeito à compreensão dos indivíduos em sua completude, o que significa assumir os educandos em suas múltiplas dimensões intelectual, afetiva, social, corpórea, objetivando favorecer um itinerário formativo, que potencialize o desenvolvimento humano em sua plenitude, que se concretiza pelo desenvolvimento da autonomia intelectual e moral. (BRASIL, 2013).

Compreendida a base que fundamenta a oferta do Ensino Médio Integrado e a Formação Humana Integral, passamos a discorrer sobre a avaliação da aprendizagem, partindo de informações históricas relacionadas à prática de exames, apresentando a avaliação formativa e confluindo com o olhar dos sujeitos da pesquisa.

\subsection{HISTÓRICO DA AVALIAÇÃO E A PRÁTICA DE EXAMES}

Pensar em avaliação nos remete a uma multiplicidade de oportunidades e circunstâncias em que ela pode ser vislumbrada enquanto prática cotidiana, como algo pontual. Ela ainda pode se configurar como possibilidade futura, quando se pretende avaliar algo ou alguém, seja antes (diagnóstica), durante (formativa), seja apenas ao término de um determinado decurso de tempo ou após a finalização de um ciclo (somativa). 
Diagnóstica, formativa e somativa constituem as três principais perspectivas ou funções da avaliação da aprendizagem. A diagnóstica proporciona as condições para o docente perceber o que os discentes conhecem sobre aquilo que se intenciona ministrar para guiar incialmente 0 planejamento e efetivar algum prognóstico nas relações entre objetivos, conteúdos e realidade sociocognitiva dos educandos (SILVA, 2003). A formativa refere-se ao que acontece durante o processo, com o objetivo de reorientação, de redimensionamento. Já a somativa implica em avaliar ou apreciar o resultado ao final do processo. (FERNANDES; FREITAS, 2007).

Para além das perspectivas diagnóstica, formativa e somativa, bem como das condições históricas acerca da temática em discussão, encontra-se uma diversidade de significados em torno da palavra avaliação, o que certamente amplia suas possibilidades de interpretação e aplicação.

Como muitas outras, a palavra "avaliação" possui múltiplos significados que dependem das diferentes perspectivas e contextos a partir dos quais se aborda o termo. Atendendo a esta polissemia do termo, entre os significados mais comuns que Ihe são atribuídos estão: verificar; interpretar; medir; entender; aprender; comparar; emitir juízos de valor; julgar; compreender; apreciar; etc. (LOPES; SILVA, 2012, p. 1).

Apesar dessa amplitude de significados em torno da avaliação, sua origem histórica no campo educacional está mais estritamente vinculada à prática de exames, à seletividade e à atribuição de notas. A avaliação, em seus primórdios, era denominada Docimologia, termo oriundo do grego dokimé (medida, nota). A Docimologia era a ciência do estudo metódico dos exames, da concessão de notas e de condutas de examinadores e examinados, e tem como principal difusor o estudioso francês Pierón. É, possivelmente, em razão dessa origem que uma grande quantidade de pessoas ainda confunde avaliação com realização exclusivamente de provas. (DEPRESBITERIS, 1998).

Embora nem sempre os atores educacionais, sobretudo docentes e discentes, apresentem diretamente uma concepção de avaliação atrelada à prática examinativa, seletiva e excludente, fica por vezes revelada a compreensão que possuem a respeito do processo avaliativo como algo ainda bastante arraigado em suas características originárias, conforme poderemos constatar quando apresentarmos o posicionamento expresso nas falas dos discentes na seção "Avaliação da aprendizagem a partir do olhar dos discentes do Ensino Médio Integrado".

Dentre as características históricas remanescentes nos espaços escolares quanto à temática em estudo, Luckesi (2011) destaca que, em relação aos exames escolares, herdamos essa metodologia avaliativa dos séculos XVI e XVII. Ela percorreu os séculos subsequentes e chegou aos dias atuais, fazendo com que as práticas escolares vigentes em nossas escolas Vol. 2 (2020) 
sejam caracterizadas pela pedagogia tradicional, estruturada no contexto dos referidos séculos.

Simultaneamente à prática de exames no âmbito da avaliação, encontra-se uma de suas principais consequências negativas: a reprovação. Ao reprovar, a escola fomenta a seletividade e, consequentemente, a exclusão daqueles que não atenderam aos critérios estabelecidos e conhecimentos cobrados e medidos por meio dos exames. Isso também se encontra relacionado aos primórdios históricos da avaliação. relata que:

Dentro desta perspectiva, Depresbiteris (1989, p. 5, grifo do autor) nos

As primeiras idéias sobre avaliação da aprendizagem estavam ligadas a idéia de medir. O uso da avaliação como medida vem de longa data. Através de Ebel, tem-se o relato de Kuo sobre a presença de exames, já em 2.205 a.C. Nessa época, o Grande "Shun", imperador chinês, examinava seus oficiais a cada três anos, com o fim de os promover ou demitir.

Apesar da indicação expressa do período em que o referido imperador chinês examinava seus oficiais, o relato em questão nos conduz naturalmente à percepção de que se está narrando um fato atual e vigente em nossas escolas e em nossa sociedade. Esse fato se dá em razão da frequente aplicação de exames, tanto na esfera das práticas pedagógicas adotadas no interior de instituições públicas e privadas de ensino (avaliações internas), quanto por exames externos, como o Sistema Nacional de Avaliação da Educação Básica - SAEB, o Exame Nacional do Ensino Médio - ENEM, os vestibulares, além dos concursos públicos (avaliações externas e em larga escala), entre outros sistemas de avaliação. Todos eles são utilizados pelas mais diversas instituições da sociedade, a fim de ranquear as instituições e os sistemas de ensino, selecionar estudantes/candidatos, elegendo os "melhores" ou "mais aptos" a dar continuidade nos estudos ou para ocupar vagas e cargos de emprego.

Em "Uma análise das avaliações em larga escala sob a perspectiva de Paulo Freire", Perboni e Di Giorgi (2013) nos encaminham à reflexão sobre as políticas de avaliação externa e em larga escala, partindo do pressuposto de que, em geral, elas objetivam mais atender aos interesses do capital do que o redimensionamento das ações de ensino em favor do desenvolvimento da educação e dos educandos. Esta proposta é totalmente contrária àquilo que Paulo Freire propõe como educação para a transformação e emancipação do ser humano. A educação por meio da avaliação deve oportunizar aos docentes e discentes o crescimento mútuo no aperfeiçoamento dos processos de ensino e aprendizagem, e não apenas medir, classificar ou ranquear resultados, objetivando atender unicamente aos interesses hegemônicos do neoliberalismo. 
De modo muito similar, Esquinsani e Dametto (2016), no artigo "Avaliações educacionais em larga escala: ponderações críticas alicerçadas na obra de Paulo Freire", recomendam reflexões a respeito da relação entre a teoria freireana e a orientação de uma visão crítica em torno das avaliações em larga escala enquanto ferramenta de política educacional. Segundo os autores, geralmente a avaliação em larga escala é caracterizada por sua ocorrência externa à rede de ensino, ao sistema educacional ou às instituições às quais possam se destinar. Ela acontece embasada na teoria de resposta ao item, a partir da aplicação de testes que atendem a um padrão específico e destinam-se a um grande público referente a determinados níveis de escolaridade e faixas etárias.

Retornando às considerações mais diretas sobre as origens da prática de exames em nossas escolas, Luckesi (2011) nos revela que até o final da Idade Média e princípio da Idade Moderna, o processo educativo escolar acontecia na relação entre um professor e um número reduzido de alunos, não havendo salas de aula com grandes quantitativos. Todavia, a partir desse período ocorre a alteração na composição das salas de aula, quando passa a existir os modelos com grandes quantidades de discentes, perdurando até a atualidade, pelo menos dentro do ensino público. É neste cenário que se começa a utilizar exames orais e escritos, como solução para 0 acompanhamento simultâneo de muitos educandos/estudantes.

A divisão do ensino em turmas de acordo com idade e aprendizagem teve início entre os anos 1549 e 1759, com o predomínio da pedagogia tradicional ligada a religião e centrada na transmissão de valores. A instrução intelectual priorizava o domínio do aspecto formal-instrumental (ler, escrever, contar) e o aspecto concreto da aprendizagem de um ofício. No conjunto das regras destinadas ao ensino (Ratio Studiorum), destacavam-se regras para professores das classes superiores e das classes inferiores, impulsionadas pelo surgimento da manufatura e divisão do trabalho e de classes, produzindo "trabalhadores especializados" nas classes inferiores e lideranças para as classes superiores. A avaliação do ensino, caracterizada pelos exames, ocupava posição central nesse processo formativo. (MACHADO; SILVA; SOUZA, 2016, p. 209).

Dentro dessa conjuntura histórica pertinente à avalição no âmbito escolar pautada na prática de exames, além do papel da Ratio Studiorum (Plano e Organização de Estudos da Companhia de Jesus) merece igual destaque as orientações oriundas da Didática Magna. A Ratio Studiorum corresponde à proposta pedagógica jesuítica, que expressa a visão católica a respeito de regras a serem cumpridas pelos sistemas de ensino, já a Didática Magna consiste na versão protestante, sistematizada pelo bispo Comênio, também em relação a regras para a educação escolar. Ambas as propostas 
foram estruturadas durante os séculos XVI e XVII, resumindo, assim, as formulações teórico-práticas da educação para o período, estando já incluso o ensino simultâneo e, consequentemente, a prática de exames. (LUCKESI, 2011).

Apesar dos referidos documentos possuírem origens ideológicoreligiosas distintas, elas carregam grandes aproximações e semelhanças, culminando para a determinação de regras a serem rigorosamente cumpridas nos espaços escolares, tendo a prática de exames um lugar de destaque. A avaliação escolar estava limitada à rigidez de exames, que, comumente, contribuíam mais para o controle, a ameaça e a exclusão do que para a verificação das reais condições de aprendizagem, isto é, para embasar uma tomada de decisão e/ou o redimensionamento do processo ensinoaprendizagem.

Diante das informações históricas relativas aos primórdios da avaliação, as quais para este estudo tiveram o objetivo apenas de proporcionar uma base para compreender a razão de ser da prática de exames, somos conduzidos a vislumbrar alternativas para a avaliação da aprendizagem, uma vez que a referida prática, oriunda entre os séculos XVI e XVII, não se mostra coerente com as reais necessidades de aprendizagem e Formação Humana Integral dos estudantes do século XXI.

\subsection{AVALIAÇÃO FORMATIVA: ALTERNATIVA À PRÁTICA DE EXAMES}

Neste artigo, não temos a pretensão de mensurar, enumerar ou mesmo exaurir todas as eventuais condições ou ações indispensáveis para superação da prática de exames, considerando que se trata de uma marca histórica no campo da avaliação, que ainda permanece fortemente impregnada na rotina de nossas escolas e em nossa sociedade, conforme apresentamos em páginas precedentes deste estudo. Todavia, para se alcançar mudanças no modo de ser da avaliação da aprendizagem, é importante que possamos defender continuamente uma postura contrária ao modo excludente e classificatório, imposto pela prática dos exames arraigada na avaliação tradicional; é preciso partir de outra perspectiva, a qual adicione contribuições necessárias ao sucesso do processo ensino-aprendizagem e Formação Humana Integral dos estudantes.

Nestas circunstâncias, destacamos o papel da avaliação dentro do viés formativo, favorável ao exercício de uma prática avaliativa voltada ao real desenvolvimento da aprendizagem e formação plena dos discentes. Essa perspectiva apresenta-se, de certo modo, contrária à avaliação tradicional, como alternativa de renovação pedagógica.

A avaliação tradicional, não satisfeita em criar fracasso, empobrece as aprendizagens e induz, nos professores, didáticas conservadoras e, nos alunos, estratégias utilitaristas. A avaliação formativa participa da renovação global da 
pedagogia, da centralização sobre o aprendiz, da mutação da profissão de professor: outrora dispensador de aulas e de lições, o professor se torna o criador de situações de aprendizagem "portadoras de sentido e de regulação". (PERRENOUD, 1999, p. 16).

Por essas ideias iniciais oriundas do pensamento de Perrenoud e extraídas da sua obra Avaliação: Da Excelência à Regulação das Aprendizagens - Entre duas lógicas, percebemos o grau de abrangência deste outro olhar sobre a avaliação da aprendizagem. Ao centralizar sua atenção sobre o aluno e tornar o professor um agente de criação de situações de aprendizagem, inverte-se a lógica avaliativa predominante, transcendendo significativamente 0 ato de examinar para atribuir uma nota, apenas selecionando e classificando os estudantes em aptos ou ineptos.

A partir do olhar formativo, ganham importância e destaque o discente, o papel pedagógico e criativo do docente no ambiente da aprendizagem, na regulação desta e na participação na renovação plena da pedagogia. Quando voltamos nosso olhar à prática de exames amparada na pedagogia e avaliação tradicional, percebemos que isso não ocorre; tampouco encontramos no tradicionalismo qualquer intenção de auxílio à aprendizagem e ao desenvolvimento do aluno, uma vez que é silenciadora do ponto de vista do discente. A esse respeito, em outro recorte da obra suprarreferenciada, constatamos que: "É formativa toda avaliação que ajuda o aluno a aprender e a se desenvolver, ou melhor, que participa da regulação das aprendizagens e do desenvolvimento no sentido de um projeto educativo". (PERRENOUD, 1999, p. 103, grifo do autor).

Construir e solidificar um projeto educativo neste sentido, orientado para a regulação das aprendizagens, redimensionando as ações de ensinoaprendizagem sempre que o processo avaliativo sinalizar para esta necessidade, não constitui uma tarefa simples. Todavia, ela se faz necessária, imperativa e urgente, demandando uma ação contínua, dinâmica e cooperativa entre os principais entes escolares: docentes e discentes.

Nesta acepção, Lopes e Silva reforçam as ideias de Perrenoud ao definirem a avaliação formativa como:

[...] um processo frequente, contínuo e dinâmico que envolve professores e alunos numa relação de cooperação, com vista a recolherem dados sobre a aprendizagem. Ambos (o professor - avaliação para a aprendizagem - e o aluno avaliação como aprendizagem) usam os dados obtidos para tomar decisões sobre que ações tomar para promover a aprendizagem futura. A medição da aprendizagem do aluno é apenas um dos seus componentes. (LOPES; SILVA, 2012, p. 6-7, grifos dos autores). 
Igualmente ressaltando os papéis de docentes e discentes na qualidade de principais protagonistas do processo educativo escolar no campo da avaliação formativa, Hadji (2001) discorre que este viés avaliativo comunica as consequências efetivas da ação pedagógica por parte do professor, possibilitando realizar sua adequação ou readequação. Ademais, permite ao discente ter consciência do seu estado atual de aprendizagem, das suas dificuldades, sendo capaz de reconhecer seus erros e realizar as correções necessárias para o desenvolvimento da sua aprendizagem.

A avaliação formativa proporciona alterações expressivas nas funções de docentes e discentes na esfera da avaliação da aprendizagem, em contraposição ao que ocorre em relação à prática de exames dentro da pedagogia e avaliação tradicional: "[...] a avaliação formativa funciona. Funciona, porque tem um efeito direto sobre os dois intervenientes mais importantes no processo de ensino-aprendizagem: o professor e o aluno". (LOPES; SILVA, 2012, p. 35).

De sujeito passivo e receptor, o discente torna-se participante ativo do processo avaliativo, ganhando voz, tornando-se ciente de seu desenvolvimento, suas insuficiências e possibilidades de avanços. Já o papel do docente não se restringe apenas à aplicação de exames para medir a aprendizagem ou classificar os discentes: além da função de regular a aprendizagem, ele passa a atentar para as informações indicativas da qualidade do seu trabalho pedagógico, podendo, sempre que se fizer necessário, redimensioná-lo no sentido de concretizar as finalidades pedagógicas de aprendizagem a que se propõe.

Especificamente quanto ao papel do professor no horizonte da avaliação formativa, Hadji (2001, p. 21) reforça que:

\begin{abstract}
A avaliação formativa implica, por parte do professor, flexibilidade e vontade de adaptação, de ajuste. Este é sem dúvida um dos únicos indicativos capazes de fazer com que se reconheça de fora uma avaliação formativa: o aumento da variabilidade didática. Uma avaliação que não é seguida por uma modificação das práticas do professor tem poucas chances de ser formativa! Por outro lado, compreende-se por que se diz frequentemente que a avaliação formativa é, antes contínua. A inscrição no centro do ato de formação se traduz, na verdade, por uma melhor articulação entre a coleta de informações e a ação remediadora.
\end{abstract}

Embora existam outras circunstâncias que exerçam influências sobre as práticas avaliativas como um todo e especificamente em relação à perspectiva formativa, o professor, enquanto mediador do processo ensino-aprendizagem e orientador das atividades pedagógicas intra e extraclasse, acaba tendo naturalmente um papel fundamental. Se pelo caráter formativo e regulador da Vol. 2 (2020) 
avaliação o docente identifica que são necessários ajustes ou redimensionamentos de sua prática pedagógica, a fim de proporcionar uma maior qualidade no aproveitamento da aprendizagem, ninguém melhor que o próprio docente para conduzir as modificações necessárias e de modo contínuo.

Mesmo possuindo papel fundamental no processo de ensinoaprendizagem e particularmente no contexto da avaliação formativa, o docente não deve ser considerado como o único responsável pelas mudanças necessárias. Outros atores ou esferas educacionais podem contribuir com o processo de modificações nas práticas pedagógico-avaliativas, por exemplo, a gestão escolar a nível estratégico, a equipe técnico-pedagógica, na condição de suporte pedagógico e operacional para as ações de ensino-aprendizagem, e a família, apoiando as mudanças na avaliação propostas pela escola. Para Vasconcellos (2014), em uma ótica democrática de organização da escola, a participação de todos os segmentos da comunidade educativa é essencial. A família deve ser instruída, no propósito de compreender que também tem uma significativa atribuição para não deturpar o sentido da avaliação.

Quanto ao caráter contínuo, também atribuído à avaliação formativa por Hadji, Vasconcellos (2014), ao tratar especificamente dessa adjetivação, justifica-a afirmando que é necessária para que a avaliação cumpra sua função de subsídio ao processo ensino-aprendizagem. Importa, portanto, a avaliação realizada no processo, à medida que o professor tem a possibilidade de acompanhar a construção do conhecimento pelo educando; avaliando no momento em que precisa ser avaliado, para auxiliá-lo a elaborar o seu conhecimento, analisando os diversos estágios de desenvolvimento e não apenas realizando um julgamento em um momento específico.

Dadas as considerações teóricas acerca da perspectiva formativa da avaliação até então apresentadas, fica evidente que reúne condições diferenciadas e mais salutares em comparação à prática de exames derivada da avaliação tradicional, especialmente quando tencionamos proporcionar aos estudantes um processo avaliativo capaz de adicionar contribuições ao desenvolvimento de sua aprendizagem e Formação Humana Integral. Para proporcionar tais condições aos estudantes, se faz necessário sair da prática de exames e caminhar na direção da avaliação em educação, sobretudo dentro de sua perspectiva formativa.

Segundo Luckesi (2011), para passar do ato de examinar para a ação de avaliar na esfera educacional, devemos atuar de maneira inclusiva, empregando esforços para que a aprendizagem seja democrática e satisfatória para todos os discentes, percorrendo um caminho em direção a modificações e, à vista disso, contrário às normas sociais já impregnadas em nossas ações.

Certamente, trabalhar pela mudança exige bem mais do que trabalhar a favor do status quo (estado atual) ${ }^{3}$ da avaliação e dos interesses sociais hegemônicos permeados em nossas consciências e manifestados em nossas ações, sobretudo no âmbito escolar e mais diretamente na dimensão avaliativa do processo ensino-aprendizagem. 
É neste contexto que, aliado à base teórica levantada, torna-se fundamental conhecermos o que pensam os discentes participantes deste estudo, a respeito da avaliação da aprendizagem, uma vez que são eles que se encontram imersos no processo ensino-aprendizagem e submetidos a algum tipo de prática avaliativa, seja ela seletiva, classificatória e excludente, seja formativa, emancipatória e includente. É o que almejamos clarificar com as informações angariadas a partir da "Metodologia" adotada, particularmente com a entrevista na condição de instrumento de coleta de dados, aliada a este referencial teórico.

\section{METODOLOGIA}

Para a elaboração deste artigo, assumimos como referenciais metodológicos um prévio levantamento teórico (pesquisa bibliográfica) seguido de um levantamento empírico (pesquisa de campo / aplicação de entrevista semiestruturada), que nos serviram de base.

Os dados teóricos foram coletados por meio de uma pesquisa bibliográfica sobre: Ensino Médio Integrado; Formação Humana Integral; o Histórico da Avaliação ligado a Prática de Exames e a Avaliação na Perspectiva Formativa. Para Marconi e Lakatos (2016, p. 57), a finalidade da pesquisa bibliográfica consiste em:

[...] colocar o pesquisador em contato direto com tudo o que foi escrito, dito ou filmado sobre determinado assunto, inclusive conferências seguidas de debates que tenham sido transcritos por alguma forma, quer publicadas quer gravadas.

Já a pesquisa de campo, para os mesmos autores, é aquela empregada com a finalidade de obter informações e/ou conhecimentos sobre um problema para o qual se busca uma resposta, ou de uma hipótese que se queira confirmar, ou, ainda, desvendar novos fenômenos ou as relações entre eles. (MARCONI; LAKATOS, 2016).

Voltando-nos para a vivência real dos sujeitos (discentes participantes da pesquisa), no intuito de obter informações sobre o fenômeno da avaliação por eles vivenciado, aplicamos uma entrevista semiestruturada. Para Manzini (2012), a entrevista semiestruturada caracteriza-se por um roteiro com perguntas abertas e é recomendada para estudar um fenômeno com uma população específica: grupo de professores, grupo de alunos, grupo de enfermeiras, etc. Deve existir flexibilidade na sequência da apresentação das perguntas ao entrevistado e o entrevistador pode realizar perguntas adicionais para entender melhor o fenômeno em pauta.

A coleta e a apresentação dos dados empíricos neste estudo se restringiram às informações obtidas apenas por meio da primeira questão que 
compõe o roteiro da entrevista ${ }^{4}$ (1a . $O$ que você entende por avaliação da aprendizagem $?^{5}$ ), dirigida a cinco discentes ${ }^{6}$ de uma turma de $3^{\circ}$ Ano do Curso Técnico de Nível Médio em Agropecuária na Forma Integrada (finalistas em 2019) do Instituto Federal de Educação, Ciência e Tecnologia do Amazonas IFAM, Campus Eirunepé ${ }^{7}$. Através do conteúdo das respostas apresentadas pelos sujeitos da pesquisa, identificamos, numa abordagem qualitativa, quais as compreensões, percepções e vivências implícitas ou mesmo explícitas em suas falas, a respeito do entendimento preponderante sobre avaliação da aprendizagem, diante do caráter histórico da prática de exames e a perspectiva formativa da avaliação. A pesquisa qualitativa tem o ambiente natural como a fonte direta de dados e o pesquisador como instrumento fundamental, constituindo como preocupação central do investigador o significado que as pessoas dão às coisas e a sua vida (FREITAS; JABBOUR, 2011).

Deste modo, amparados pelo percurso metodológico ora descrito, angariamos as informações necessárias para identificar e compreender o que nos revelou os olhares dos discentes do Ensino Médio Integrado sobre a avaliação da aprendizagem.

\section{AVALIAÇÃO DA APRENDIZAGEM A PARTIR DO OLHAR DOS DISCENTES DO ENSINO MÉDIO INTEGRADO}

As considerações teóricas advindas de diversos e renomados autores no campo da avaliação traduzem, comumente, como se dá ou como poderia ser a avaliação da aprendizagem no âmbito escolar, tendo em vista que, em

\footnotetext{
${ }^{4} \mathrm{Na}$ pesquisa de mestrado, o roteiro da entrevista semiestruturada está composto por 12 (doze) questões.

${ }^{5} \mathrm{~A}$ resposta para esta questão será reapresentada dentro da dissertação de mestrado. No entanto, sua análise se dará em conjunto com as demais questões abordadas na entrevista, inclusive com a participação de um número maior de discentes.

${ }^{6}$ A realização deste estudo, como parte das ações desenvolvidas durante a pesquisa de mestrado, foi previamente aprovado pelo Comitê de Ética em Pesquisa - CEP, vinculado à Plataforma Brasil, conforme Parecer Consubstanciado do CEP, sob o no. 3.529.280, de 23.08.2019. Com isso, os discentes e/ou seus responsáveis legais (quando menor de 18 anos) assinaram os respectivos Termos de Assentimento Livre e Esclarecido - TALE e/ou Termos de Consentimento Livre e Esclarecido - TCLE. Neste sentido, para preservação da identidade dos discentes, eles foram codificados respectivamente em: DISCENTE 01, 02, 03, 04 e 05, seguida da informação " $3^{\circ}$ Ano, 2019", em referência à série e ao ano letivo em curso à época da coleta de dados.

${ }^{7}$ O IFAM Campus Eirunepé faz parte do processo de Expansão da Rede Federal de Educação Profissional e Tecnológica - Fase III. Sua autorização de funcionamento foi expedida em 09 de maio de 2016, por meio da Portaria no. 378/2016, do Ministério da Educação. Este campus está instalado no município de Eirunepé, Estado do Amazonas, situado a $1.245 \mathrm{~km}$ em linha reta da cidade de Manaus, a capital do Estado (Disponível em: http://www.idam.am.gov.br/municipio/eirunepe/. Acesso em: 23 jan. 2020). De acordo com o IBGE o município possui um Índice de Desenvolvimento Humano Municipal - IDHM de 0,563 e uma população total estimada em 35.273 habitantes (Disponível em: https://www.ibge.gov.br/cidades-e-estados/am/eirunepe.html. Acesso em: 23 jan. 2020). 
geral, as proposições teóricas são consequências de pesquisas e/ou experiências empíricas sobre o assunto.

Neste sentido, embasados inicialmente no levantamento bibliográfico apresentado no Referencial Teórico deste estudo, voltamos nossa atenção para o olhar do discente sobre a avaliação da aprendizagem, pois se encontram submetidos a alguma proposta pedagógica-educativa e, consequentemente, avaliativa dentro do universo escolar, portanto, podem se manifestar sobre 0 assunto. Para tanto, conforme já mencionamos anteriormente, as informações empíricas coletadas para a produção deste artigo se deram no contexto de uma entrevista semiestruturada, por meio do seguinte questionamento direcionado aos discentes participantes da pesquisa: "O que você entende por avaliação da aprendizagem?".

Ao ser questionado, o Discente 01 (3ํNO, 2019) respondeu que:

Eu entendo por avaliação da aprendizagem como um fator assim para determinar o conhecimento adquirido né. $O$ professor passa os conhecimentos e de tal forma ele vai querer ver se a gente aprendeu mesmo. E para isso tem que ter uma avaliação.

O entendimento do discente está vinculado à educação tradicional ou padronizada ("o professor passa os conhecimentos"), ganhando a avaliação caráter de medida ou classificação ("determinar o conhecimento adquirido") relacionada à aplicação de algum instrumento avaliativo ("tem que ter uma avaliação"). Esta compreensão, ao tempo que revela um modo de pensar a educação e a avaliação ligadas às características tradicionais e padronizadas, muito próximas à prática histórica de exames, nos desafia a buscar alternativas, a fim de abrir possibilidades de vivenciar a avaliação e gerar uma nova compreensão sobre o tema em questão, de forma contextualizada.

De acordo com Silva (2019, p. 63),

[...] o desafio é superar a concepção e a prática de uma educação padronizada, onde o papel do professor era e ainda é de transmitir linearmente conteúdos prontos e acabados, do aluno de reproduzir saberes e da avaliação era e é, predominantemente, de notificar, classificar, selecionar, excluir, consequentemente, punir.

Na mesma linha de percepção da avaliação da aprendizagem inclinada à prática de exames, também se encontra a resposta do Discente 02 (3ํAㅇ, 2019), para quem a avaliação "é quando o professor passa um trabalho ou 
exercício. E é baseado nesse trabalho ou exercício que ele vai ver nossa aprendizagem". Esse juízo encontra-se ainda mais caracterizado pelo viés da avaliação tradicional ao direcionar o entendimento sobre avaliação simplesmente para o ato de examinar utilizando algum instrumento ("trabalho ou exercício") como forma de medir a aprendizagem.

Também precisamos ter claro que não são exatamente os instrumentos que determinam se a avaliação é classificatória ou formativa, mas suas finalidades. Quais objetivos devem nortear os instrumentos, o processo avaliativo em particular e o processo ensino-aprendizagem de modo geral? As respostas a estas, entre outras interrogações, podem determinar a que tipo de avaliação submetemos ou pretendemos submeter o corpo discente. Para Luckesi (2011), é preciso verificar se os instrumentos em uso são convenientes às finalidades estabelecidas por nós, se eles possuem um nível apropriado de qualidade metodológica suficiente para angariar as informações necessárias para realizarmos a prática da avaliação da aprendizagem.

Para o Discente 03 (3ำ ANO, 2019), a avaliação da aprendizagem corresponde a:

Um método do professor testar se o que ele aplicou foi adquirido pelos alunos, se foi absorvido. É também uma forma dele poder observar o rendimento da turma e saber se a gente tá realmente preparado pro que tem na vida lá fora, pela concorrência que vai ter.

Esta afirmação, além de realçar novamente o caráter de medida ("testar"), sinaliza para outra importante questão relacionada à visão que os discentes constroem a respeito do papel da escola: preparar para a vida além da escola, para a concorrência.

Dentro desta concorrência acaba estando inclusa a prática de exames extraescolares (vestibulares, processos seletivos e concursos públicos, por exemplo) aos quais os estudantes precisarão se submeter para o seu crescimento acadêmico e profissional. Com isto, aquilo que a escola pratica e exige internamente em relação aos exames acaba estando, em grande parte, alinhado àquilo que a sociedade burguesa cobra constantemente.

A prática dos exames escolares é profundamente adequada ao modo de ser da sociedade burguesa, pois se apresenta compatível com o seu modelo teórico e prático de organização e de vida. Nesse contexto, não há nenhuma razão, a não ser por posição ideológica consistente, para buscar um modo de ser em educação que aja contra esse modelo. (LUCKESI, 2011, p. 260). 
Nesse sentido, os Discentes 04 e 05 (3ำ ANO, 2019) mantêm a percepção da avaliação da aprendizagem enquanto medida, pois endossam as falas dos colegas anteriormente apresentadas ao afirmarem que: "Avaliação pra mim é, o professor usa esse método pra medir os nossos conhecimentos né, a maioria deles é pra ver se realmente a gente entendeu o assunto, se a gente prestou atenção, se a gente conseguiu fixar alguma coisa", conforme o Discente 04. O Discente 05 , por sua vez, afirma que a avaliação da aprendizagem "é um meio de avaliar nosso aprendizado. Tipo, se a gente tá saindo bem, se a gente tá absorvendo o conteúdo. Aí os professores passam avaliação pra ver se a gente tá aprendendo realmente o assunto".

No contexto geral, em cada recorte das falas dos sujeitos aqui apresentadas, predomina uma compreensão de avaliação da aprendizagem atrelada à prática de exames, como recurso para medir o nível de desempenho. Embora os entrevistados não tenham utilizado explicitamente o termo exame, o conteúdo de suas falas transmite características do ato de examinar, por exemplo, ao destacarem a avaliação a partir das seguintes afirmações: "Determinar o conhecimento adquirido" (DISCENTE 01, $3^{\circ}$ ANO, 2019); "é quando o professor passa um trabalho ou exercício" (DISCENTE 02, $3^{\circ}$ ANO, 2019); "método do professor testar se o que ele passou foi adquirido pelos alunos" (DISCENTE 03, 3 ANO, 2019); "método para medir os conhecimentos" (DISCENTE 04, $3^{\circ}$ ANO, 2019); "se a gente tá absorvendo o conteúdo" (DISCENTE 05, 3ํAㅇ, 2019).

Diante dessas informações, ratifica-se o pensamento de Luckesi (2011, p. 202), quando afirma que:

\begin{abstract}
A prática escolar usualmente denominada de avaliação da aprendizagem pouco tem a ver com avaliação. Ela constitui-se muito mais de provas/exames do que de avaliação. Provas/exames têm por finalidade, no caso da aprendizagem escolar, verificar o nível de desempenho do educando em determinado conteúdo. [...] Desse modo, provas/exames separam os "eleitos" dos "não eleitos". Assim sendo, essa prática exclui uma parte dos alunos e admite, como "aceitos", uma outra. Manifesta-se, pois, como uma prática seletiva.
\end{abstract}

Deste modo, verificamos que é preciso caminhar em uma nova direção, buscando alternativas para proporcionar melhores condições ao processo avaliativo, a partir de outro olhar sobre avaliação da aprendizagem, a qual tenha como meta o sucesso indistinto de todos os alunos. Essa abordagem precisa assumir o ato de avaliar não para excluir, mas para incluir e adicionar contribuições ao processo de aprendizagem e Formação Humana Integral do discente.

A perspectiva formativa da avaliação se opõe à avaliação tradicional, compreendida por meio da classificação e medida. Ela diferencia-se em razão de sua ação constante de interpretação, intervenção, aprimoramento e 
redirecionamento, proporcionando meios viáveis para o êxito do processo ensino-aprendizagem. (LUIS, 2003).

Ao almejar o aprimoramento e o redirecionamento do desenvolvimento do ensino-aprendizagem, esta função da avaliação se distancia das características históricas da avaliação ligada à prática de exames, balizada na classificação e medida, ao tempo que se aproxima do atendimento das reais necessidades de aprendizagem e Formação Humana Integral dos discentes. Trata-se, neste caso, de um processo avaliativo a favor do aluno e não do mero estabelecimento de uma medida para classificá-los em aptos ou ineptos. Visto que, todos precisam progredir no desenvolvimento de sua aprendizagem para alcançarem o sucesso na escola e na vida, independentemente das profissões e papéis sociais que vierem a ocupar e desenvolver na sequência de suas vidas para além dos muros escolares.

Para Perrenoud (1999), a ideia de avaliação formativa leva o professor a analisar mais sistematicamente os alunos, a compreender melhor seus funcionamentos, ajustando de modo mais metódico e individualizado suas intervenções pedagógicas e as situações didáticas que recomenda, tudo isso na expectativa de otimizar as aprendizagens.

Do exposto, constatamos, por um lado, que o entendimento preponderante entre o corpo discente sobre a avaliação da aprendizagem está relacionado ao caráter de medida decorrente da prática de exames. Por outro lado, tal constatação nos impele a recorrer e defender a avaliação formativa como opção avaliativa mais coerente para atender aos ideais de aprendizagem e Formação Humana Integral dos discentes.

\section{CONSIDERAÇÕES FINAIS}

Dado o itinerário percorrido neste estudo, destacamos que o objetivo estabelecido de "compreender a percepção dos discentes do Ensino Médio Integrado sobre avaliação da aprendizagem, frente ao caráter histórico da prática de exames e a perspectiva formativa da avaliação" foi atendido. Pois, a partir das falas dos discentes, identificamos a compreensão de uma avaliação associada à finalidade de medir e classificar, derivada da prática de exames.

Em decorrência dessa percepção dos discentes e contrapondo-nos a esta característica, concluímos também que se faz necessário projetar um olhar distinto das amarras históricas da prática de exames, potencialmente mais coerente com as necessidades de aprendizagem e Formação Humana Integral dos estudantes. É neste contexto que "levantamos a bandeira" da avaliação formativa.

Por conseguinte, os principais resultados encontrados com esta investigação se concentraram basicamente nestes dois pontos, a saber: 1 - 0 olhar discente revelou uma compreensão da avaliação enquanto prática de exames, e 2 - a perspectiva formativa da avaliação, em contraposição à prática de exames, se apresentou como alternativa para concretizar um processo avaliativo mais favorável à aprendizagem e à Formação Humana Integral dos discentes. 
Ao apresentamos a história da avaliação no espaço escolar relacionada à prática de exames, verificamos que avaliar e examinar em determinados momentos ou circunstâncias ainda acabam sendo tratados como sinônimos (LUCKESI, 2011), inclusive estando implícito nas falas dos entrevistados.

Já a avaliação formativa, na condição de opção à mera prática de exames, sinalizou para uma propositura avaliativa mais propensa à formação e aperfeiçoamento, objetivando a transformação dos sujeitos (BATISTA, 2011), a partir de características inclusivas, reguladoras e emancipatórias (PERRENOUD, 1999). Consequentemente, essa concepção de avaliação se coaduna com a intencionalidade da Formação Humana Integral na esfera do Ensino Médio Integrado, que consiste, entre outras coisas, em proporcionar uma formação completa para a leitura do mundo e atuação cidadã. (CIAVATTA, 2005).

Ao confluir as informações teóricas levantadas com as falas dos discentes, identificamos a presença da compreensão da avaliação como ação de medir e classificar relacionada à prática de exames, ao tempo em que somos impelidos ao desafio de caminhar na direção da avaliação formativa. Isso não constitui uma tarefa simples, todavia, é necessária, se almejamos consolidar um processo avaliativo a favor do aluno e não da simples apresentação de resultados quantitativos derivados da prática de exames.

Neste contexto, a contribuição desta pesquisa para a avaliação da aprendizagem no âmbito do Ensino Médio Integrado decorre da exposição do olhar dos discentes sobre a avaliação. A visão apresentada por eles sinaliza para a necessidade de evolução do processo avaliativo em outra direção, uma vez que a realidade retratada não se harmoniza com os propósitos de desenvolvimento pleno do discente almejados pela EPT. Revela-se latente a necessidade de aprofundamento do debate em torno da avaliação, na expectativa de consolidação de alternativas avaliativas mais salutares para todos, especialmente para discentes e docentes. Com isto, entre as alternativas possíveis, foi que defendemos a avaliação formativa.

Assim, embora este estudo nos tenha conduzido a algumas constatações relevantes quanto ao entendimento predominante dos discentes do Ensino Médio Integrado a respeito da avaliação da aprendizagem, reconhecemos que ainda há muito que se pesquisar e discutir acerca da temática para que possamos avançar em direção à consolidação de um processo avaliativo capaz de se tornar "um degrau" e não "uma pedra" para o alcance do sucesso da aprendizagem e Formação Humana Integral dos discentes.

\section{REFERÊNCIAS}

\section{BATISTA, C. O (Org.). A Dimensão Dialógica da Avaliação Formativa.} Jundiaí: Paço Editorial, 2011.

BEMVINDO, V.; ALMEIDA, C.; TURRINI, C. Formação Humana no Instituto Politécnico da UFRJ: o trabalho como princípio educativo a partir da pedagogia de projetos. Trabalho Necessário, ano 11, n. 16, p. 1-30, 2013. 
Disponível em:

http://periodicos.uff.br/trabalhonecessario/article/view/8451/6051. Acesso em: 03 mar. 2020.

BEZERRA, D. de S. Ensino Médio (des)integrado: história, fundamentos, políticas e planejamento curricular - Natal (RN): IFRN, 2013. Disponível em: http://portal.ifrn.edu.br/pesquisa/editora/livros-para-download/ensino-mediodes-integrado-digital. Acesso em: 04 jun. 2019.

BRASIL. Resolução CNE/CEB № 6, de 20 de setembro de 2012. Define Diretrizes Curriculares Nacionais para a Educação Profissional Técnica de Nível Médio. Diário Oficial da União, Brasília, 21 set. 2012, Seção 1, p. 22. Disponível em:

http://portal.mec.gov.br/index.php?option=com_docman\&view=download\&alia $\mathrm{S}=11663$-rceb006-12-pdf\&category_slug=setembro-2012-pdf\&Itemid=30192. Acesso em: 15 jan. 2019.

BRASIL. MEC. Concepções e Princípios. Educação Profissional Técnica de Nível Médio Integrada ao Ensino Médio. Documento base. Brasília, 2007. Disponível em: portal.mec.gov.br/setec/arquivos/pdf/documento_base.pdf. Acesso em: 17 set. 2018.

BRASIL. SEB. Formação de professores do ensino médio, etapa I caderno III; o currículo do ensino médio, seu sujeito e o desafio da formação humana integral. Curitiba: UFPR/Setor de Educação, 2013. Disponível em: http://www.observatoriodoensinomedio.ufpr.br/wpcontent/uploads/2014/03/Caderno-3-O-curriculo-do-ensino-medio.pdf. Acesso em: 03 mar. 2020.

CIAVATTA, M. A Formação Integrada. A escola e o trabalho como lugares de memória e de identidade. Trabalho Necessário, ano 3, n. 3, p. 1-20, 2005. Disponível em:

http://periodicos.uff.br/trabalhonecessario/article/view/6122/5087. Acesso em: 19 set. 2018.

DEPRESBITETIS, L. Avaliação de programas e avaliação da aprendizagem. Educação e Seleção. n.19, p. 5-31 1989. Disponível em: http://publicacoes.fcc.org.br/ojs/index.php/edusel/article/view/2639/2590. Acesso em: 03 jan. 2019.

DEPRESBITETIS, L. Confissões de uma educadora: o longo caminho de um aprendizado da avaliação. Estudos em Avaliação Educacional. São Paulo. v.18, 1998. p. 33-67. Disponível em:

http://publicacoes.fcc.org.br/ojs/index.php/eae/article/view/2251. Acesso em: 28 jun. 2015.

ESQUINSANI, R. S. S.; DAMETTO, J. Avaliações educacionais em larga escala: ponderações críticas alicerçadas na obra de Paulo Freire. Espaço Pedagógico. v. 23, n. 1, Passo Fundo, p. 205-217, jan-jun. 2016. Disponível em: http://seer.upf.br/index.php/rep/article/view/6365. Acesso em: 11 maio 2019.

ESTRELA, S. C. Educação Profissional e Formação Omnilateral: Das Escolas de Artífices ao Projeto de Ensino Integrado do Instituto Federal Goiano Campus Posse. In: VI Seminário Nacional sobre Profissionalização 
Docente, 2017, Curitiba. Disponível em: educere.bruc.com.br/arquivo/pdf2017/26119_13252.pdf. Acesso em: 19 jun. 2019.

FERNANDES, C. de O.; FREITAS, L. C. de. Indagações sobre currículo: currículo e avaliação. In: Beauchamp, J.; PAGEL, S. D.; Nascimento, A. R. (Org.). 1. ed. Brasília: Ministério da Educação, 2007, v. 1. Disponível em: http://portal.mec.gov.br/seb/arquivos/pdf/Ensfund/indag5.pdf. Acesso em: 15 jun. 2019.

FREITAS, W. R. S.; JABBOUR, C. J. C.; Utilizando estudo de caso(s) como estratégia de pesquisa qualitativa: boas práticas e sugestões. Estudo \& Debate. v.18, n.2, p. 07-22, 2011. Disponível em: http://univates.br/revistas/index.php/estudoedebate/article/view/560/550. Acesso em: 03 jan. 2020.

HADJl; C. Avaliação desmistificada. Porto Alegre: Artmed, 2001. LOPES, J.; SILVA, H. S. 50 Técnicas de Avaliação Formativa. Lisboa: Lidel, 2012.

LUCKESI, C. C. Avaliação da aprendizagem: componente do ato pedagógico. 1. ed. São Paulo: Cortez, 2011.

LUCKESI, C. C. Avaliação da Aprendizagem escolar: estudos e proposições. 22. ed. São Paulo: Cortez, 2011.

LUIS, S. M. B. De que avaliação precisamos em Arte e Educação Física? In: SILVA, J. F. da; HOFFMANN, J.; ESTEBAN, M. T. (org.). Práticas avaliativas e aprendizagens significativas em diferentes áreas do currículo. 4. ed. Porto Alegre: Mediação, 2003.

MACHADO, I. F.; SILVA, R. M.; SOUZA, M. L. J. Avaliação de Aprendizagem nos Contornos do Currículo Integrado no Ensino Médio. Cad. Cedes. Campinas, v. 36, n. 99, p. 207-221, maio-ago. 2016. Disponível em: http://www.scielo.br/pdf/ccedes/v36n99/1678-7110-ccedes-36-99-00207.pdf. Acesso em: 09 mar. 2019.

MARCONI, M. de A.; LAKATOS, E. M. Técnicas de pesquisa: planejamento e execução de pesquisas, amostragem e técnicas de pesquisa, elaboração, análise e interpretação de dados. 7. ed. São Paulo: Atlas, 2016.

MANZINI, E. J. Uso da entrevista em dissertações e teses produzidas em um programa de pós-graduação em educação. Revista Percurso - NEMO. Maringá, v. 4, n. 2, p. 149- 171, 2012. Disponível em: https://repositorio.unesp.br/bitstream/handle/11449/114753/ISSN217733002012-04-02-149-171. pdf?sequence=1\&isAllowed=y. Acesso em: 03 jan. 2020. PERBONI, F.; DI GIORGI, C. A. G. Uma análise das avaliações em larga escala sob a perspectiva de Paulo Freire. Colloquium Humanarum, v. 10, n. Especial, Jul-Dez, 2013, p. 11324-1332. Disponível em:

http://www.unoeste.br/site/enepe/2013/suplementos/area/Humanarum/Educa \%C3\%A7\%C3\%A30/UMA\%20AN\%C3\%81LISE\%20DAS\%20AVALIA\%C3\%8 7\%C3\%95ES\%20EM\%20LARGA\%20ESCALA\%20SOB\%20A\%20PERSPEC TIVA\%20DE\%20PAULO\%20FREIRE.pdf . Acesso em: 13 maio 2019. 
PERRENOUD, P. Avaliação: da excelência à regulação das aprendizagens, entre duas lógicas. Porto Alegre: ArtMed, 1999.

RAMOS, M. Concepção do Ensino Médio Integrado. In: ARAÚJO, R. M. L, PORTO, A. M. N de S \& TEODORO, E. G. (ORG). O Ensino Médio Integrado no Pará como Política Pública. Belém: SEDUC, 2008. Disponível em: https://docplayer.com.br/7108526-Concepcao-do-ensino-mediointegrado-marise-ramos.html. Acesso em: 18 set. 2018.

RAMOS, M. N. Ensino Médio Integrado: Lutas Históricas e Resistências em tempos de Regressão. 2017. In: ARAÚJO, A. C.; SILVA, C. N. N. da. (orgs.). Ensino médio integrado no Brasil: fundamentos, práticas e desafios. 1 ed. Brasília: IFB, 2017.

SILVA, C. C. da; SILVA, A. T. M. C. da; OLIVEIRA, A. K. S. de. Processo Avaliativo em Estágios Supervisionados: uma contribuição para o estudo. Cogitare Enfermagem (UFPR), v. 12, p. 428-438, 2007. Disponível em: https://revistas.ufpr.br/cogitare/article/view/10065/6919 Acesso em: 03 mar. 2020.

SILVA, J. F. da. Avaliação do Ensino e da Aprendizagem numa Perspectiva Formativa Reguladora. In: SILVA, J. F. da; HOFFMANN, J.; ESTEBAN, M. T. (org.). Práticas avaliativas e aprendizagens significativas em diferentes áreas do currículo. 4. ed. Porto Alegre: Mediação, 2003.

SILVA, J. F. da. Avaliação formativa: pressupostos teóricos e práticos. 5. ed. Porto Alegre: Mediação, 2019.

VASCONCELLOS, C. S. Avaliação: concepção dialética-libertadora do processo de avaliação escolar. 20. ed. São Paulo: Libertad, 2014. 